\title{
Desenvolvimento da Habilidade de Escrita de Relatórios Técnicos utilizando Avaliações Colaborativas e Rubricas
}

\section{Title: Development of Technical Reports Writing Ability using Online Peer Assessments and Scoring Rubrics}

Tiago Oliveira

Universidade Federal de São Paulo

tiagoooli@yahoo.com.br

José Jailson Santos Craibas

Universidade Federal de São Paulo

jailson.craibas@gmail.com

\author{
Denise Stringhini \\ Universidade Federal de São Paulo \\ dstring@gmail.com
}

\author{
Deborah Godoy Martins Corrêa \\ Universidade Federal de São Paulo \\ deborahgcorrea@gmail.com
}

\begin{abstract}
Resumo
Neste artigo, apresenta-se uma metodologia de ensino baseada em uma combinação das técnicas de avaliação colaborativa e rubrica com o objetivo de permitir que os alunos acompanhem e avaliem os trabalhos de seus pares buscando um ambiente educacional mais favorável ao desenvolvimento de habilidades de comunicação escrita. A metodologia foi aplicada em um curso de graduação, sendo que os trabalhos produzidos pelos alunos foram avaliados por especialista e a qualidade educacional do ensino empregado foi mensurada por meio do instrumento multidimensional de avaliação do ensino mundialmente conhecido como "Students' Evaluation of Educational Quality"(SEEQ). Os resultados obtidos mostram-se promissores em dois aspectos: ao ter influenciado os alunos na confecção de melhores relatórios técnicos como consequência do aprendizado se comparados a metodologia tradicional (ponto de vista do professor) e; ter produzido uma melhora estatística significativa e mais uniforme na percepção dos alunos sobre a qualidade educacional empregada na disciplina (ponto de vista dos alunos).

Palavras-chave: metodologia de ensino-aprendizagem; avaliação por pares; rubricas; habilidade de comunicação escrita; relatórios técnicos.
\end{abstract}

\begin{abstract}
In this article, we present a teaching methodology structured in a combination of online peer assessment and scoring rubric techniques with the objective of allowing students to follow and evaluate their peers work, attempting to find a more favorable educational environment focused on the development of written communication skills. The methodology was applied in an undergraduate course and the students' assignment was evaluated by a specialist and the educational quality of the teaching process was measured by means of the multidimensional evaluation instrument of education known as "Students' Evaluation of Educational Quality" (SEEQ). The results obtained have been promising in two aspects: by influencing the students to produce better technical reports as learning outcomes in contrast to tradicional methodology (teacher's point of view); have produced a statistically significant and more uniform improvement in the students' perception of the educational quality used in the course (students' point of view).
\end{abstract}

Cite as: Oliveira, T., Stringhini, D., Craibas, J. J. S. \& Corrêa, D. G. M. (2020). Development of Technical Reports Writing Ability using Online Peer Assessments and Scoring Rubrics (Desenvolvimento da Habilidade de Escrita de Relatórios Técnicos utilizando Avaliações Colaborativas e Rubricas). Brazilian Journal of Computers in Education (Revista Brasileira de Informática na Educação - RBIE), 28, 166-190. DOI: 10.5753/RBIE.2020.28.0.166. 
Keywords: teaching methodology; online peer assesment; scoring rubrics; written communication skills; technical reports. 


\section{Introdução}

A comunicação escrita é uma ferramenta fundamental em diversas situações para o sucesso profissional (França, 2013). Um profissional, de qualquer área, precisa conhecer bem seu idioma e suas normas de escrita para ser capaz de elaborar textos concisos e bem organizados que transmitam de forma clara objetivos, realização de projetos, pontos de vista, intenções, entre outras informações.

Devido a importância de se desenvolver a habilidade de escrita em alunos de cursos de graduação no Brasil, nos referenciais orientadores de currículos de diversos cursos de graduação tem-se incluído a necessidade de comunicação escrita nos perfis de egressos. Como exemplo, o MEC aprovou a resolução CNE/CES n. 11 em 2002, instituindo diversas diretrizes para todos os cursos de graduação em engenharia do país, onde pode-se destacar o inciso VIII do artigo 4 sobre competências e habilidades gerais de um engenheiro: comunicar-se eficientemente nas formas escrita, oral e gráfica. Outro exemplo que pode ser citado refere-se ao documento orientador de formação para cursos de graduação em Computação (Zorzo et al., 2017) publicado em 2017 pela Sociedade Brasileira de Computação (SBC) contendo a descrição do perfil de egresso para alunos de computação, destacando-se: ser capaz de se expressar verbalmente e na forma escrita; e de avaliar corretamente seus resultados e de terceiros. Saber transferir conhecimento e se manter atualizado.

Este artigo traz uma metodologia de ensino-aprendizagem por meio de avaliações colaborativas e o uso combinado de rubricas com a intenção de permitir ou estimular o desenvolvimento da habilidade de escrita nos alunos na confecção de relatórios técnicos, buscandose uma alternativa mais eficaz em relação aos métodos tradicionais empregados nos currículos de cursos de graduação.

Vale ressaltar que este artigo é uma extensão da versão publicada no Simpósio Brasileiro de Informática na Educação (SBIE) do Congresso Brasileiro de Informática na Educação (CBIE). No artigo publicado no SBIE (Oliveira, Stringhini, Craibas, \& Corrêa, 2018), aborda-se a metodologia de ensino-aprendizagem do ponto de vista do professor responsável à sua aplicação, retratando o desempenho dos alunos em relação às suas habilidades de escrita. Por sua vez, na versão estendida aqui descrita, além de se descrever o desempenho dos alunos, também aborda-se o ponto de vista dos alunos, verificando e analisando a percepção dos alunos sobre a qualidade, a adequação e a eficiência da metodologia empregada, utilizando-se, para isso, psicométricas definidas em instrumentos multidimensionais de avaliação do ensino.

Na sequência, na seção 2, são introduzidos os conceitos de avaliação colaborativa e de rubricas como métodos de ensino-aprendizagem. Na seção 3, define-se a metodologia de ensinoaprendizagem mencionada anteriormente e, na seção 4, especifica-se o emprego dessa metodologia em uma disciplina de Laboratório de Arquitetura e Organização de Computadores de um curso de Engenharia de Computação. Na seção 5, apresentam-se os resultados de desempenho obtidos pelos alunos com a aplicação dessa metodologia, comparando-os com o desempenho de turmas 
submetidas à metodologia tradicional (ponto de vista do professor). Realiza-se também uma análise da qualidade educacional empregada percebida pelos alunos, comparando os resultados com turmas submetidas à metodologia tradicional (ponto de vista dos alunos). Além disso, comentam-se sobre as vantagens e limitações do ambiente virtual de aprendizagem utilizado na aplicação dessa metodologia. Por fim, na seção 6, encontram-se as considerações finais sobre a metodologia aplicada e os trabalhos futuros a serem realizados.

\section{Fundamentação Teórica}

\subsection{Avaliação Colaborativa}

A avaliação colaborativa ou avaliação por pares (Tenório, Bittencourt, Isotani, \& Silva, 2016) é uma alternativa a avaliação tradicional, buscando unir a etapa de avaliação ao processo de ensinoaprendizagem do aluno e permitindo ao aluno o acompanhamento, a avaliação e a regulação da sua própria aprendizagem.

A avaliação colaborativa pode ser definida como um cenário em que alunos atuam na revisão de trabalhos de outros alunos de mesmo nível por meio de um acordo ou conjunto de critérios definidos pelo professor (Trahasch, 2004; Topping, 2006). Enquanto avaliados, seus trabalhos são revisados pelos colegas e, enquanto avaliadores, realizam retorno sobre os trabalhos de seus colegas. Todo esse processo pode possibilitar que os alunos pensem mais profundamente sobre determinado assunto, conduzindo-os a uma aprendizagem mais significativa (Trahasch, 2004), onde professor e aluno podem refletir sobre os objetivos alcançados e adotar medidas para a superação de dificuldades em direção aos objetivos desejados. Além disso, quando um aluno avalia trabalhos desenvolvidos por seus colegas, indiretamente, o aluno está aprendendo a se autoavaliar e a ajustar o seu próprio trabalho em direção aos objetivos estabelecidos, desenvolvendo assim senso crítico e capacidade de análise e de reflexão sobre os objetivos desejados e alcançados. Assim, a avaliação passa a ser uma compilação de ações e intenções, centrada no aluno e não no professor.

A avaliação colaborativa tem sido aplicada com sucesso no ensino superior em áreas diversificadas, podendo-se citar, como exemplos, o trabalho publicado em (Wang, Li, Feng, Jiang, \& Liu, 2012) sobre o uso dessa prática de ensino na área de linguagens de programação em Computação, o trabalho publicado em $(\mathrm{Ng}, 2014)$ para a formação de professores, o trabalho publicado em (Garousi, 2010) numa disciplina relacionada a engenharia e os trabalhos nacionais publicados em (Silva \& Moreira, 2003) e (Ugulino, Marques, Pimentel, \& Siqueira, 2009) relacionados a aplicação da avaliação colaborativa em cursos de graduação e pós-graduação em, respectivamente, disciplinas de computação e uma disciplina de Metodologia de Pesquisa Científica. 


\subsection{Rubricas}

Uma definição comumente utilizada para rubrica refere-se a um documento que descreve a articulação das expectativas de uma determinada tarefa, listando-se os critérios ou quesitos que devem ser analisados e descrevendo-se os níveis de qualidade desejáveis em relação a cada um dos critérios discriminados (Reddy \& Andrade, 2010). Essas tarefas podem corresponder aos mais variados tipos de objetos ou artefatos de aprendizagem, tais como, produtos ou protótipos, apresentações orais, mapas de conceitos, artigos, pôsteres e exames.

Esta prática de ensino pode ser incluída em dois contextos educacionais, quais sejam: na avaliação dos alunos e no processo de ensino-aprendizagem. No primeiro contexto, os artefatos produzidos pelos alunos podem ser avaliados e as rubricas utilizadas para aferição e estabelecimento de uma determinada nota ou conceito final relacionado a qualidade de cada um ou de um conjunto desses artefatos produzidos (Campbell, n.d.). No segundo contexto, ao se disponibilizar antecipadamente critérios bem definidos e delineados da avaliação e os seus níveis de desempenho desejáveis, as rubricas podem ser utilizadas para facilitar a produção de retornos formativos (feedbacks) sobre o progresso dos alunos (Andrade, 2000), além de servir como guia do processo de aprendizagem do próprio aluno, permitindo-o utilizar as rubricas como parâmetro no desenvolvimento, revisão e julgamento de seus trabalhos (Huba \& Freed, 2000).

Como exemplos de rubricas no ensino superior podem-se citar o desenvolvimento de um conjunto de ferramentas de software para facilitar a aplicação no ensino do quadro europeu de qualificações (European Qualifications Framework - EQF) relacionado ao processo de Bolonha (Florian-Gaviria, Glahn, \& Fabregat Gesa, 2013); a aplicação de rubricas para avaliação e para o aprendizado em cursos da área de economia (McGoldrick \& Peterson, 2013); e os trabalhos nacionais sobre a avaliação de um Web fórum por meio de rubricas num curso de graduação em Ciências Biológicas (Ferreira \& Silva, 2010) e sobre a avaliação qualitativa de estudantes em cursos de computação e pedagogia (Lobato, Brito, Souza, \& Favero, 2009).

\section{Definição da Metodologia de Ensino}

O uso combinado da avaliação colaborativa e de rubricas pode ser estruturado para permitir o aprimoramento da habilidade de escrita em disciplinas que apresentem em seus conteúdos programáticos a execução de experimentos, o desenvolvimento de projetos ou a realização de tarefas/atividades que possam ser descritas por meio de relatórios técnicos.

A ideia é subdividir a disciplina em estágios ou pontos de checagem (PCs), sendo que no final de cada PC é realizada uma avaliação do progresso do aluno. Em cada um dos pontos de checagem, relatórios técnicos devem ser confeccionados pelos alunos da turma e um processo de avaliação colaborativa deverá ser realizado.

Quanto ao processo de avaliação colaborativa, relatórios técnicos confeccionados pelos 
alunos devem ser distribuídos entre seus pares para avaliação. A cada novo PC, novos relatórios técnicos são confeccionados e, por consequência, atribuídos aos alunos para avaliação.

Para nortear e balizar o processo de avaliação colaborativa realizado pelos alunos, um modelo de ficha de avaliação, apresentado na tabela 1, foi elaborado para o relatório técnico. Sendo assim, uma ficha de avaliação deve ser preenchida pelos alunos durante o processo de avaliação colaborativa, permitindo aos alunos conhecerem previamente os assuntos que deverão ser abordados em seus relatórios técnicos e como esses relatórios serão avaliados. Vale a pena observar que inclusões ou modificações no modelo de ficha de avaliação elaborado podem e devem ser realizadas para que se adequem aos objetivos esperados e as especificidades de cada PC definido.

Nesta tabela, observa-se que o modelo de ficha de avaliação elaborado estrutura-se em nove dimensões, quais sejam: cabeçalho, introdução, objetivos, fundamentação teórica, desenvolvimento do trabalho, resultados obtidos e discussão, considerações finais, referências bibliográficas e aspectos gerais. Para cada dimensão existe um conjunto de perguntas e uma seção final de comentários. Por sua vez, para cada pergunta existe uma escala ou estratificação de pontuação, devendo os alunos assinalar uma dentre as estratificações disponíveis para cada pergunta de acordo com a qualidade das respostas encontradas no relatório técnico que está em análise. Além disso, no final de cada dimensão, é de extrema importância que os alunos preencham a seção de comentários, descrevendo os pontos fortes e os pontos fracos da dimensão em análise, explicitando possíveis melhorias ou caminhos a serem percorridos.

A metodologia de ensino estrutura-se numa combinação de rubricas e avaliações colaborativas com o intuito de (1) permitir aos alunos acompanharem os trabalhos que estão sendo desenvolvidos por outros alunos e observarem as diversas estratégias adotadas, os caminhos que estão sendo seguidos, as ferramentas que estão sendo utilizadas e as dificuldades que estão sendo encontradas pelos seus pares; (2) possibilitar que os alunos interajam entre si, propondo novos caminhos, alternativas e relatando seus pontos de vistas sobre os trabalhos que estão sendo desenvolvidos pelos seus pares, buscando-se, com isso, uma aprendizagem mais significativa e; (3) desenvolver nos alunos senso crítico e capacidade de auto-avaliação e auto-reflexão ao analisarem os trabalhos que estão sendo desenvolvidos pelos seus pares e, por consequência, seus próprios trabalhos.

\section{Aplicando a Metodologia de Ensino na Prática}

Na Universidade Federal de São Paulo - Unifesp, o ensino de arquitetura e organização de computadores está inserido num currículo de curso de Engenharia de Computação diferenciado, estruturado em uma abordagem prática e sistêmica que busca, além de integrar teoria e prática e também hardware e software, reduzir a visão fragmentada dos alunos de um sistema computacional complexo. Mais detalhes sobre essa estrutura curricular diferenciada da Unifesp podem ser 
Tabela 1: Modelo de ficha de avaliação elaborado para o relatório técnico.

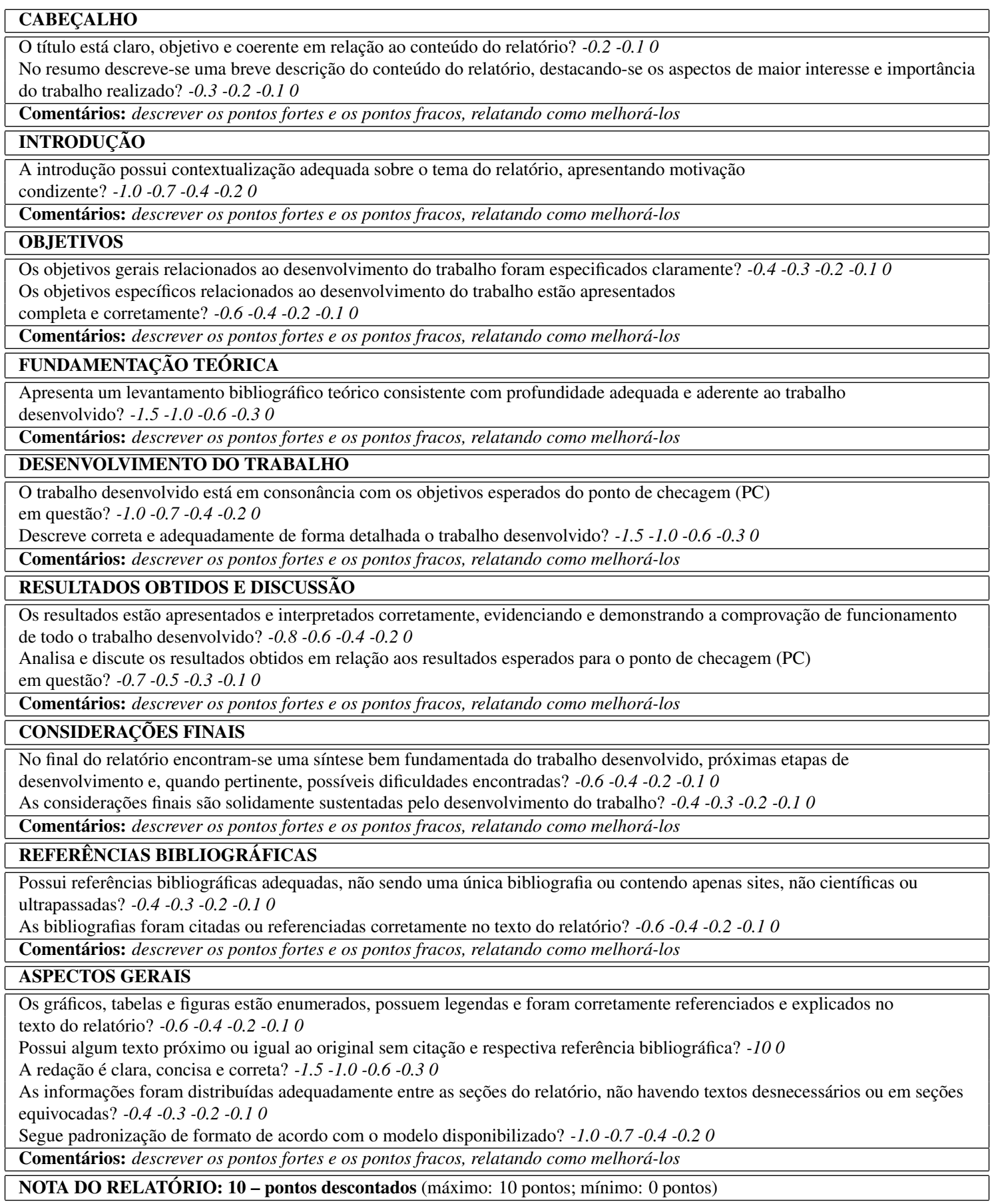

encontrados no projeto pedagógico do curso $^{1}$ e no artigo publicado em

${ }^{1} \mathrm{O}$ projeto pedagógico do curso de graduação em Engenharia de Computação da Unifesp foi aprovado em 2015 e pode ser encontrado pelo endereço eletrônico http://www.unifesp.br/campus/sjc/o-curso-engcom/projeto- 
(Oliveira, Martins, Stringhini, Fazenda, \& Cappabianco, 2017).

Dentro dessa estrutura encontra-se a disciplina de Laboratório de Arquitetura e Organização de Computadores, a qual ocorre em 4 horas semanais durante vinte semanas para turmas de 25 alunos, onde cada aluno deve desenvolver em linguagem de descrição de hardware Verilog sua própria plataforma de hardware, composta por processador, memória e sistema de entrada/saída utilizando um kit didático específico.

Para o cumprimento desses objetivos, a metodologia de ensino foi subdividida em quatro pontos de checagem (PCs), sendo eles: no primeiro ponto de checagem (PC1) os alunos são estimulados a pesquisar o funcionamento e arquitetura interna de vários processadores da literatura e a começarem a definir o conjunto de instruções (ISA) que será suportado pela sua plataforma de hardware; no segundo ponto de checagem (PC2) o aluno deve realizar um detalhamento maior do esboço da arquitetura interna e projetar em Verilog a unidade de processamento da plataforma de hardware; no terceiro ponto de checagem (PC3) o aluno deve realizar a especificação em Verilog da unidade de controle da plataforma de hardware proposta e, por fim, no quarto e último ponto de checagem (PC4) o aluno deve trabalhar na integração de todos os módulos produzidos, interligando a unidade de processamento e de controle da plataforma de hardware.

Em cada um dos quatro pontos de checagem, um relatório técnico deve ser confeccionado por aluno e um processo de avaliação colaborativa deverá ser realizado. Quanto ao processo de avaliação colaborativa, são atribuídos seis relatórios técnicos por aluno. A cada novo PC, atribuem-se relatórios técnicos de diferentes alunos, buscando-se evitar a repetição de alunos em relação aos pontos de checagem anteriores para um determinado avaliador. Sendo assim, no final da disciplina, um aluno terá analisado 24 relatórios técnicos de alunos diferentes, o que permite ao aluno ter tido contato com os projetos que estão sendo desenvolvidos por todos os alunos da turma, já que a disciplina possui no máximo 25 alunos no total.

Por fim, o ambiente virtual de aprendizagem Moodle $^{2}$ foi utilizado para suportar a aplicação da metodologia de ensino, tendo sido organizado para permitir a realização, o mapeamento e a submissão das atividades propostas em cada ponto de checagem. O ambiente virtual Moodle foi escolhido por ser a plataforma institucional adotada na Unifesp, facilitando a configuração de contas, gerenciamento de conteúdo, agendamento e programação de atividades, distribuição de mensagens, aplicação das rubricas e realização da avaliação colaborativa. Além disso, os alunos já estão familiarizados com essa plataforma por a terem utilizado em outras unidades curriculares.

pedagogico-do-curso.html, acessado em 03/09/2018.

${ }^{2} \mathrm{O}$ Moodle (Modular Object-Oriented Dynamic Learning Environment) é uma plataforma computacional de código aberto utilizado como apoio à aprendizagem do aluno. Mais detalhes sobre essa plataforma podem ser encontrados no endereço eletrônico https://moodle.org, acessado em 03/09/2018. 


\section{Resultados Obtidos e Discussão}

\subsection{Análise de Desempenho}

Para analisar a qualidade dos relatórios técnicos produzidos pelos alunos por meio da avaliação colaborativa e rubricas utilizadas, como proposto na metodologia de ensino da seção 3 , foi realizada uma comparação das notas dos alunos no último relatório produzido por eles durante quatro anos de oferecimento da disciplina de Laboratório de Arquitetura e Organização de Computadores (representados pelas turmas 01, 02, 03 e 04). Para todas as turmas, o último relatório de cada aluno foi entregue para um especialista da área que atribuiu uma nota de avaliação.

Para as turmas 03 e 04 foram aplicadas a metodologia de ensino proposta neste artigo, enquanto que para as turmas 01 e 02 foi adotada uma metodologia de ensino tradicional: durante o semestre, após a ocorrência de aproximadamente $\frac{1}{3}, \frac{1}{2}, \frac{3}{4}$ e no final da unidade curricular, um relatório técnico era produzido por cada aluno. As correções desses relatórios, realizadas pelo professor responsável, eram entregues aos alunos contendo erros produzidos na redação dos textos dos relatórios, erros de especificação e implementação dos projetos e, quando necessário, instruções a serem realizadas para um realinhamento ou reposicionamento dos projetos para o correto desenvolvimento das plataformas de hardware.

Sendo assim, na figura 1, encontra-se a média das notas obtidas pelas turmas 01, 02, 03 e 04 em relação ao último relatório técnico produzido pelos alunos da disciplina. No total, como tamanho das amostras, 17 relatórios técnicos foram entregues pela turma 01, enquanto 18 relatórios foram entregues em cada uma das demais turmas analisadas.

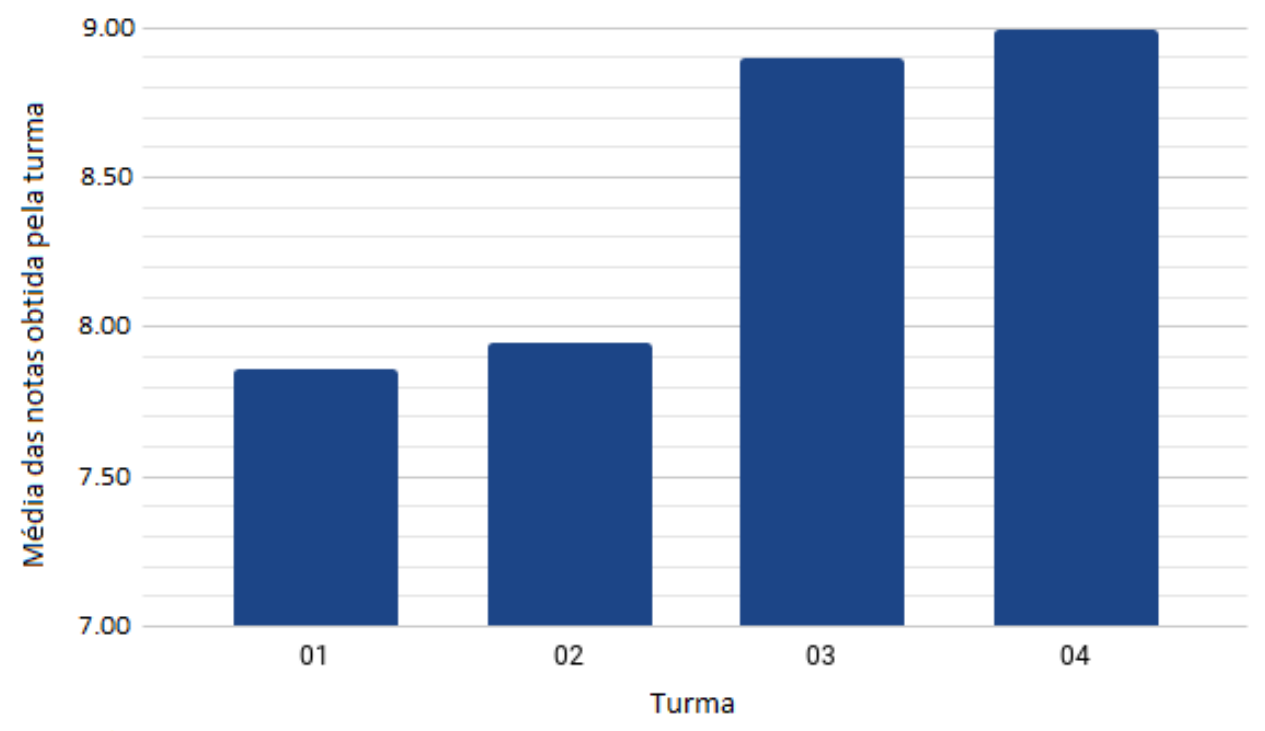

Figura 1: Desempenho das turmas em relação ao último relatório técnico elaborado durante a realização da disciplina. 
Para a turma 01, a média das notas obtidas no último relatório técnico elaborado pelos alunos foi de aproximadamente 7,86, para a turma 02 a média foi de aproximadamente 7,95, para a turma 03 a média foi de aproximadamente 8,90 e para a turma 04 a média foi de aproximadamente 8,99. Portanto, com a aplicação da metodologia de ensino proposta, o desempenho dos alunos, representado pela média das notas obtidas no último relatório técnico produzido, é superior ao desempenho dos alunos que cursaram a disciplina na abordagem tradicional.

Uma informação estatística interessante pode ser relacionada a confiabilidade e a robustez das amostras obtidas referentes às notas dos relatórios técnicos produzidos pelos alunos das turmas 01, 02, 03 e 04 no final da disciplina, buscando-se comprovar estatisticamente a melhora na habilidade de escrita dos alunos que foram submetidos a metodologia de ensino proposta. Devido a dimensão das amostras $(<30)$ e a utilização de escalas ordinais de medida (escala likert de 5 pontos), o teste estatístico não paramétrico Wilcoxon-Mann-Whitney, apresentado na figura 2, foi realizado com o auxílio da linguagem de programação $\mathrm{R}^{3}$ para verificar a equivalência entre $\mathrm{o}$ desempenho dos alunos na confecção dos relatórios técnicos. Nesta figura, encontram-se todas as combinações possíveis de comparação de desempenho entre as quatro turmas ofertadas.

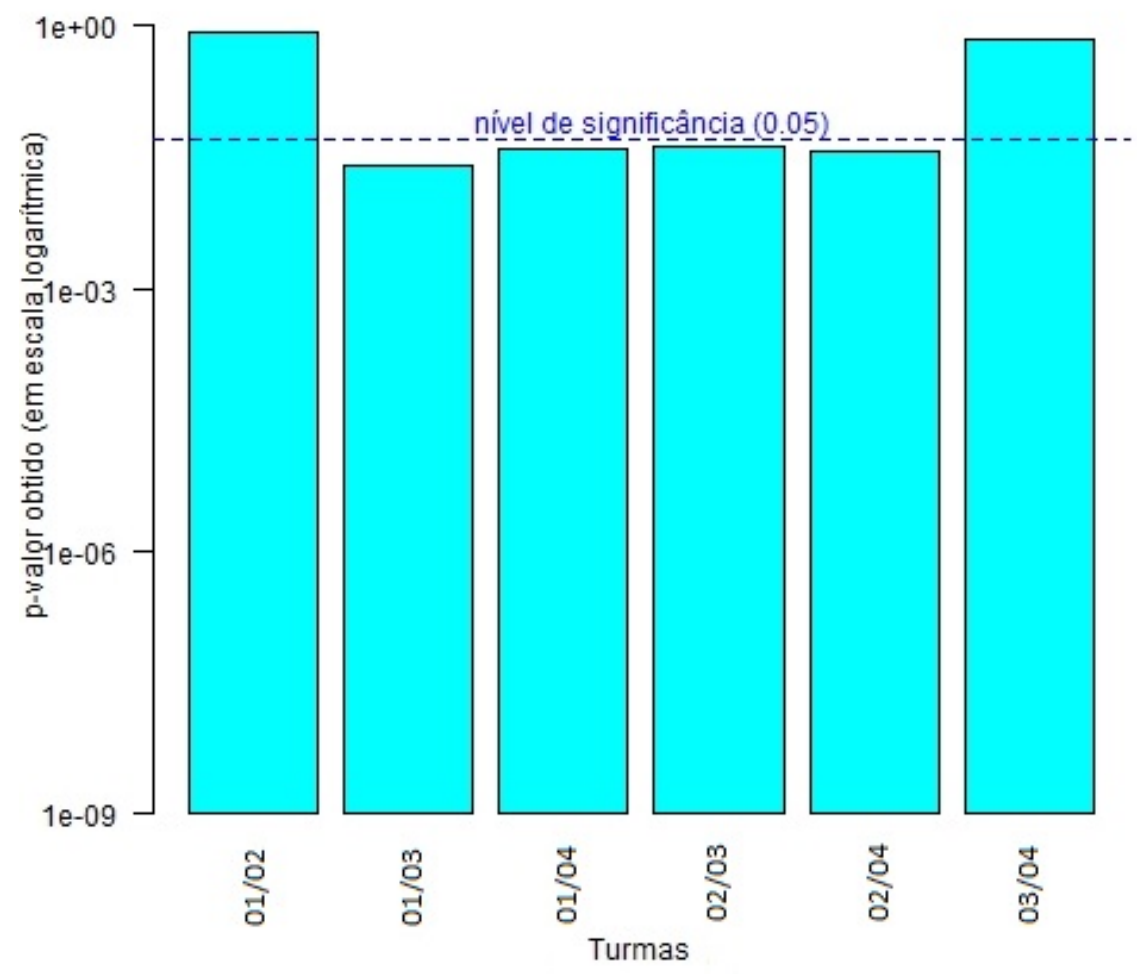

Figura 2: Teste de Wilcoxon-Mann-Whitney quanto à equivalência das amostras.

\footnotetext{
${ }^{3} \mathrm{O}$ software R utilizado é gratuito e implementa uma linguagem de programação específica além de um ambiente de desenvolvimento integrado para cálculos estatísticos e geração de gráficos. Para mais detalhes, consulte a página oficial do projeto R: https://www.r-project.org/, acessado em 12/06/2018.
} 
Diante do gráfico apresentado na figura 2, a comparação estatística da turma 01 com a turma $03(01 / 03)$, da turma 01 com a turma $04(01 / 04)$, da turma 02 com a turma $03(02 / 03)$ e da turma 02 com a turma $04(02 / 04)$ resultou em p-valores menores do que o nível de significância de 0,05 delineado (linha tracejada no gráfico), rejeitando-se, portanto, a hipótese nula de equivalência entre as turmas. Por sua vez, a comparação estatística entre as turmas 01 e $02(01 / 02)$ e entre as turmas 03 e 04 (03/04) gerou p-valores maiores do que o nível de significância estabelecido $(0,05)$, aceitando-se, portanto, a hipótese nula e evidenciando a equivalência das amostras comparadas.

Particularmente esse resultado estatístico demonstra a confiabilidade e robustez das amostras, já que sinaliza claramente uma diferença entre os desempenhos dos alunos em relação às suas habilidades de escrita quando se comparam duas turmas submetidas a metodologias de ensino diferentes. Vale observar que, na figura 2, sempre que a comparação estatística ocorre entre uma turma 01 ou 02 (metodologia de ensino tradicional) com uma turma 03 ou 04 (metodologia de ensino proposta neste artigo), aponta-se para uma diferença estatística significativa entre as turmas analisadas. Diferentemente do que ocorre ao se comparar a turma $01 \mathrm{com}$ a turma 02 (ambas turmas submetidas a metodologia de ensino tradicional) ou ao se comparar a turma 03 com a turma 04 (ambas turmas submetidas a metodologia de ensino proposta), pois nestes dois casos não se observam diferenças estatísticas significativas entre as turmas analisadas.

Quanto a validade da análise sobre a melhora na habilidade de escrita dos alunos, o teste estatístico realizado anteriormente não é suficiente, fazendo-se necessário também verificar se o desempenho dos alunos das turmas 03 e 04, os quais foram submetidos a metodologia de ensino proposta, é estatisticamente superior ao desempenho dos alunos que cursaram a disciplina com a aplicação da metodologia tradicional, representados pelas turmas 01 e 02.

Para tanto, levando em consideração que as amostras referentes às turmas 01 e 02 não possuem diferença estatística significante para o nível de significância delineado, como pode ser observado na figura 2, e que, além disso, pertencem a aplicação de uma mesma metodologia de ensino, pode-se combiná-las para formar um único conjunto de dados contendo o desempenho dos alunos submetidos a aplicação da metodologia de ensino tradicional. Este conjunto de dados é, portanto, composto pela junção das amostras de desempenho da turma 01 e também da turma 02. De maneira análoga, pode-se combinar em um único conjunto de dados o desempenho obtido nas turmas 03 e 04, já que ambas as turmas foram submetidas a aplicação da metodologia de ensino proposta e não apresentam diferenças estatísticas significantes, de acordo com a figura 2.

Ao aplicar o teste estatístico por meio da linguagem $\mathrm{R}$ levando em consideração a hipótese alternativa de superioridade sobre o conjunto de dados contendo o desempenho combinado dos alunos das turmas 03 e 04 em comparação com o desempenho combinado dos alunos das turmas 01 e 02, como mencionado no parágrafo anterior, obtém-se o p-valor de aproximadamente 0,001301. Dessa forma, para o nível de significância delineado em 0,005, aceita-se a hipótese alternativa, comprovando-se a melhora na habilidade de escrita dos alunos que foram submetidos a metodologia de ensino proposta neste artigo.

De acordo com os parágrafos anteriores, numa visão quantitativa, a análise estatística 
utilizando o teste de superioridade realizado demonstrou melhora das turma 03 e 04 em relação às turmas 01 e 02 nas notas atribuídas aos relatórios técnicos. No entanto, para além dos conceitos atribuídos, faz-se importante comentar algumas diferenças que foram notadas entre as turmas 01/02 e as turmas 03/04 durante o processo de análise dos relatórios técnicos, numa visão mais qualitativa dos trabalhos produzidos pelos alunos.

Com a aplicação da metodologia de ensino tradicional (turmas 01 e 02) observou-se uma melhora mais significativa em relação às especificações técnicas da plataforma de hardware, porém uma melhora menos acentuada em relação aos recursos linguísticos e de estilo utilizados pelos alunos em seus relatórios técnicos para expressarem suas ideias, desenvolvimentos, acontecimentos e intenções.

Por sua vez, para as turmas 03 e 04, as quais foram submetidas à metodologia de ensino proposta neste artigo, notou-se não apenas uma melhora em relação às questões técnicas da plataforma de hardware, mas também foram observadas melhora significativa no detalhamento e na explicação de todo o sistema desenvolvido, imprimindo uma melhor fluidez de leitura nos relatórios técnicos produzidos.

Possivelmente, isso possa estar relacionado ao fato dos alunos, ao participarem do processo de avaliação colaborativa, terem sido expostos a variados estilos de escrita e de recursos linguísticos que se encontram em outros relatórios técnicos, permitindo-os enriquecer seus reportórios de redação em relação à plataforma de hardware projetada. Por exemplo, os alunos vão modificando, adaptando e incluindo em seus próprios relatórios técnicos, novas tabelas, gráficos, esquemáticos, detalhamentos e aprofundamentos de tópicos por meio da observação e aprendizado ocorrido ao analisarem outros relatórios técnicos quando do processo de avaliação colaborativa em cada um dos quatro pontos de checagem (PC1, PC2, PC3 e PC4). Com isso, os alunos acabam elaborando relatórios técnicos mais bem fundamentados e com uma linguagem descritiva mais rica e expressiva.

\subsection{Análise da Qualidade Educacional}

Um questionário de avaliação sobre a qualidade educacional ou efetividade do ensino foi aplicado e respondido pelos alunos ao final da disciplina. $\mathrm{O}$ questionário pôde ser preenchido eletronicamente de forma anônima e não-obrigatória, tendo sido publicado no Moodle por uma semana durante o término da unidade curricular.

O questionário aplicado baseia-se no instrumento multidimensional de avaliação do ensino pelos alunos mundialmente conhecido como Students' Evaluation of Educational Quality (SEEQ) (Marsh, 1982). O SEEQ, além de ser utilizado em diversas universidades no mundo e ter propriedades psicométricas bem conhecidas (Coffey \& Gibbs, 2001), tem sua validade e reprodutibilidade sido confirmadas internacionalmente em diversos países (Richardson, 2005).

No questionário aplicado, apresentado na tabela 2, os alunos indicam seu grau de concordância numa escala de resposta likert de 5 pontos sobre 32 afirmações agrupadas em nove 
dimensões relacionadas à efetividade do ensino, sendo eles: aprendizado, entusiasmo, organização, interação com o grupo, empatia, amplitude na abordagem, processo de avaliação, atividades/atribuições e carga de trabalho/dificuldade. Para as oito primeiras dimensões a estratificação da escala segue o padrão: 1 correspondendo a "discordo plenamente", 2 correspondendo a "discordo", 3 correspondendo a "não concordo nem discordo", 4 correspondendo a "concordo" e 5 correspondendo a "concordo plenamente". Para a última dimensão, a estratificação da escala é definida em conjunto com a afirmação realizada, sendo que a estratificação de maior valor numérico indica uma maior carga de trabalho ou dificuldade encontrada durante a realização da disciplina. Além disso, o questionário também possui uma questão em aberto, permitindo que o aluno descreva os pontos positivos que considerou ter sido relevantes para o seu aprendizado e os pontos que precisam ser melhorados.

Na figura 3 apresentam-se os resultados obtidos com a aplicação desse questionário nas turmas $01,02,03$ e 04 . Vale a pena ressaltar que, para as turmas 03 e 04 quando a metodologia de ensino proposta foi utilizada, os alunos foram previamente instruídos a responderem o questionário onde a expressão "professor", em determinadas afirmações, teve seu significado ampliado. Por exemplo, na afirmação 25 ("Os comentários do professor sobre as provas e trabalhos corrigidos foram importantes"), a expressão "professor" poderia significar tanto o professor responsável pela disciplina quanto os próprios alunos da turma no papel de avaliadores quando do processo de avaliação colaborativa.

O questionário foi respondido por 21 alunos da turma 01,23 alunos da turma 02, 23 alunos da turma 03 e 22 alunos da turma 04, de um total de 25 alunos em cada uma dessas turmas. Na figura 3 encontra-se a média das respostas obtidas em cada umas das nove dimensões do questionário aplicado para as turmas 01, 02, 03 e 04. Além disso, no gráfico da figura 3, discrimina-se também a média total (total geral) obtida com a aplicação do questionário para cada uma das quatro turmas, agrupando, para isso, as médias das nove dimensões e calculando a sua média geral.

De acordo com o gráfico da figura 3 apresentado, pode-se analisar o comportamento da disciplina em relação a percepção dos alunos sobre o ensino quando da aplicação da metodologia proposta. Como pode ser observado, com exceção da empatia que praticamente manteve-se sem alteração, todas as dimensões do questionário tiveram sua pontuação aumentada nas turmas 03 e 04. Vale ressaltar que as dimensões que tiveram um aumento de pontuação mais significativo foram: o aprendizado com um aumento médio de aproximadamente 0,98 pontos na escala likert entre a dupla de turmas 01 e 02 para a dupla de turmas de 03 e 04; organização com um aumento médio de aproximadamente 1,16 pontos entre as turmas 01 e 02 para as turmas 03 e 048 ; interação com o grupo com um aumento médio de aproximadamente 1,99 pontos entre as turmas 01 e 02 para as turmas 03 e 04; amplitude na abordagem com um aumento médio de aproximadamente 0,43 pontos entre as turmas 01 e 02 para as turmas 03 e 04; e o processo de avaliação com um aumento médio de aproximadamente 0,38 pontos entre as turmas 01 e 02 para as turmas 03 e 04 . No total geral, as turmas 01 e 02 obtiveram uma média geral de aproximadamente 3,48 e 3,45 pontos, respectivamente, enquanto que as turmas 03 e 04 tiveram um acréscimo médio de 0,62 
Tabela 2: Questionário de avaliação sobre a qualidade educacional aplicado aos alunos.

\begin{tabular}{|c|c|c|}
\hline \multicolumn{3}{|r|}{ Adaptado de (Marsh, 1982) } \\
\hline Dimensão & Num. & Questão/Afirmação \\
\hline \multirow{4}{*}{$\begin{array}{l}\text { Aprendizado } \\
\text { (Learning) }\end{array}$} & 1 & Você considerou a disciplina intelectualmente desafiadora e estimulante \\
\hline & 2 & Você aprendeu algo que considera importante \\
\hline & 3 & Seu interesse no conteúdo aumentou como consequência desta disciplina \\
\hline & 4 & Você aprendeu e entendeu os materiais de apoio (slides, livros, etc.) desta disciplina \\
\hline \multirow[t]{4}{*}{$\begin{array}{l}\text { Entusiasmo } \\
\text { (Enthusiasm) }\end{array}$} & 5 & $\begin{array}{l}\text { O professor era entusiasmado em relação ao ensinamento dos conteúdos } \\
\text { curriculares da disciplina }\end{array}$ \\
\hline & 6 & O professor foi dinâmico e enérgico na condução da disciplina \\
\hline & 7 & A disciplina foi realizada com simpatia e bom senso pelo professor \\
\hline & 8 & $\begin{array}{l}\text { O modo como o professor ministrou a disciplina manteve seu interesse durante } \\
\text { todo o período }\end{array}$ \\
\hline \multirow{4}{*}{$\begin{array}{l}\text { Organização } \\
(\text { Organisation })\end{array}$} & 9 & As explicações do professor eram claras \\
\hline & 10 & $\begin{array}{l}\text { Os materiais didáticos da disciplina estavam bem preparados e foram cuidadosamente } \\
\text { explicados }\end{array}$ \\
\hline & 11 & $\begin{array}{l}\text { Os objetivos apresentados estavam em consonância com aqueles realmente ensinados, } \\
\text { permitindo-me entender o percurso da disciplina }\end{array}$ \\
\hline & 12 & O planejamento da disciplina realizado pelo professor facilitou a assimilação do conteúdo \\
\hline \multirow[t]{4}{*}{$\begin{array}{l}\text { Interação com o Grupo } \\
\text { (Group Interaction) }\end{array}$} & 13 & $\begin{array}{l}\text { Os alunos foram incentivados a contribuir com outros alunos da turma durante a realização } \\
\text { da disciplina }\end{array}$ \\
\hline & 14 & Os alunos foram estimulados a compartilhar suas ideias, conhecimentos ou pontos de vista \\
\hline & 15 & Os alunos foram encorajados a fazer perguntas e receberam respostas relevantes \\
\hline & 16 & Os alunos foram incentivados a expressar suas próprias ideias \\
\hline \multirow{4}{*}{$\begin{array}{l}\text { Empatia } \\
\text { (Individual Rapport) }\end{array}$} & 17 & O professor era amistoso e cordial com os alunos, individualmente \\
\hline & 18 & $\begin{array}{l}\text { O professor fazia os alunos sentirem-se bem vindos ao pedir ajuda e conselho, dentro } \\
\text { ou fora da aula }\end{array}$ \\
\hline & 19 & O professor tinha um interesse sincero nos alunos, individualmente \\
\hline & 20 & O professor era adequadamente acessível aos alunos durante a realização da disciplina \\
\hline \multirow{4}{*}{$\begin{array}{l}\text { Amplitude na Abordagem } \\
\text { (Breadth) }\end{array}$} & 21 & Em relação ao conteúdo, foi possível identificar e comparar as implicações de várias teorias \\
\hline & 22 & O contexto ou a origem dos conceitos foram trabalhados na disciplina \\
\hline & 23 & Foram apresentados outros pontos de vista além do seu, quando apropriado \\
\hline & 24 & Com a realização da disciplina, os avanços na área puderam ser estabelecidos \\
\hline \multirow{3}{*}{$\begin{array}{l}\text { Processo de Avaliação } \\
\text { (Examinations) }\end{array}$} & 25 & Os comentários do professor sobre as provas e trabalhos corrigidos foram importantes \\
\hline & 26 & Os métodos de avaliação eram justos e apropriados \\
\hline & 27 & Os conteúdos das provas e trabalhos estavam de acordo com os enfatizados pelo professor \\
\hline \multirow{2}{*}{$\begin{array}{l}\text { Atividades/Atribuições } \\
\text { (Assignments) }\end{array}$} & 28 & O material de estudo e/ou bibliografia recomendados foram importantes \\
\hline & 29 & $\begin{array}{l}\text { As leituras, listas de exercícios, trabalhos de pesquisa, tarefas realizadas, etc. contribuíram } \\
\text { para a compreensão e apreciação dos conteúdos curriculares da disciplina }\end{array}$ \\
\hline \multirow[t]{3}{*}{$\begin{array}{l}\text { Carga de Trabalho/ Dificuldade } \\
(\text { Overall })\end{array}$} & 30 & $\begin{array}{l}\text { A dificuldade desta disciplina, em relação às outras disciplinas, foi: } \\
\text { (1- Muito fácil; } 2 \text { - fácil; } 3 \text { - Média; } 4 \text { - Difícil; } 5 \text { - Muito difícil) }\end{array}$ \\
\hline & 31 & $\begin{array}{l}\text { A exigência/carga de trabalho desta disciplina, em relação às outras disciplinas foi: } \\
\text { (1 - Muito leve; } 2 \text { - Leve; } 3 \text { - Média; } 4 \text { - Pesada; } 5 \text { - Muito pesada) }\end{array}$ \\
\hline & 32 & $\begin{array}{l}\text { O ritmo de andamento da disciplina foi: } \\
\text { (1 - Muito lento; } 2 \text { - Lento; } 3 \text { - Médio; } 4 \text { - Rápido; } 5 \text { - Muito rápido) }\end{array}$ \\
\hline $\begin{array}{l}\text { Comentários } \\
\text { (Questão em Aberto) }\end{array}$ & 33 & $\begin{array}{l}\text { Por favor, descreva os pontos positivos que você considera ter sido relevantes para o } \\
\text { aprendizado da disciplina e os pontos que precisam ser melhorados }\end{array}$ \\
\hline
\end{tabular}

pontos, alcançando patamares próximos a 4,1 pontos.

Uma informação estatística interessante refere-se ao desvio padrão produzido em cada uma das 32 afirmações do questionário da tabela 2 aplicado nas quatro turmas oferecidas, como apresentado na figura 4.

De acordo com o gráfico da figura 4, nota-se que, em linhas gerais, as turmas 03 e 04 obtiveram desvios padrão relativamente menores para a maioria das afirmações do questionário SEEQ, o que pode ser observado nas afirmações $2,6,8,9,10,11,12,13,15,16,17,18,19$, 


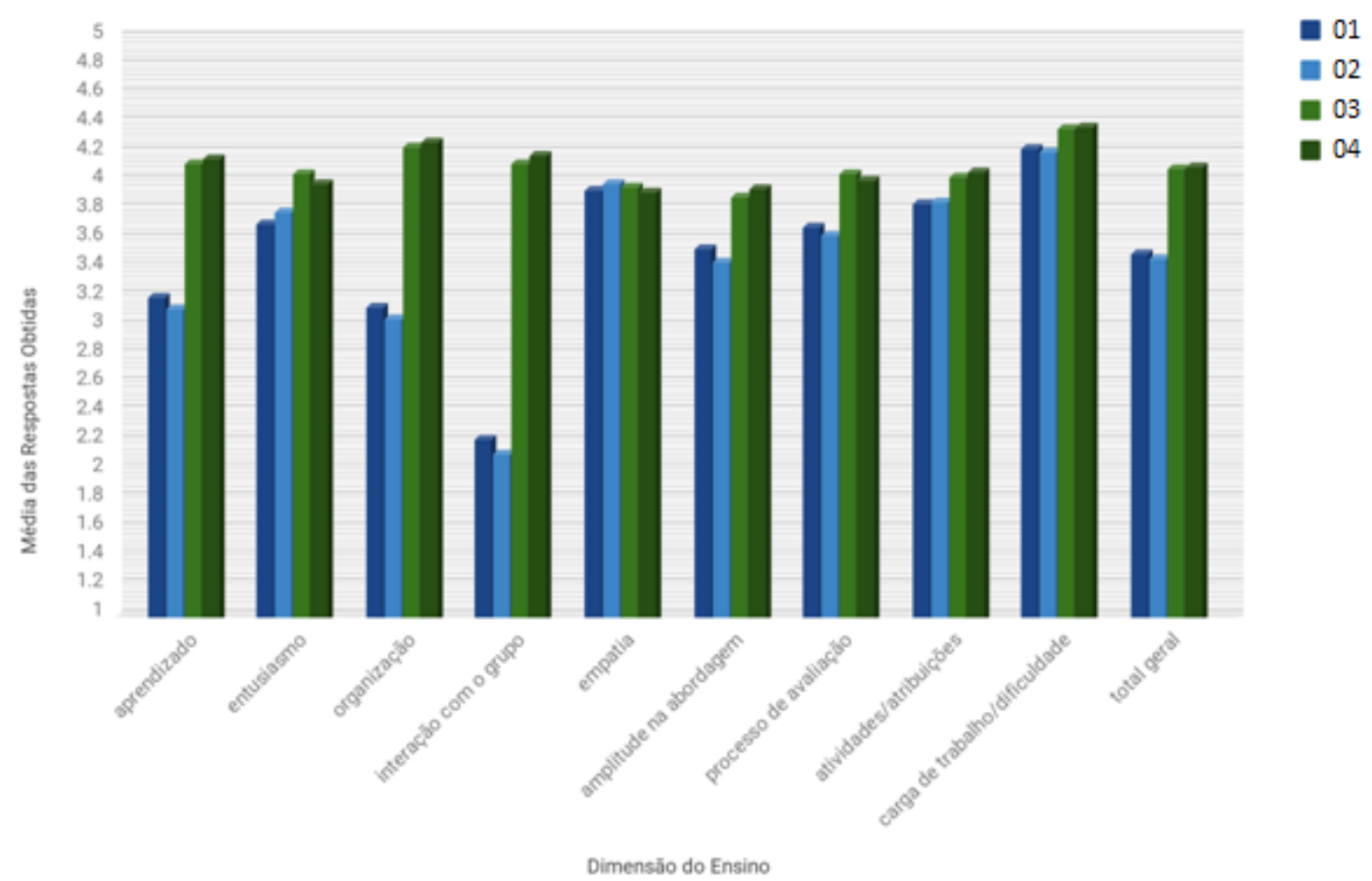

Figura 3: Média das respostas obtidas em cada dimensão para as turmas 01, 02, 03 e 04.

20, 22, 23, 25, 26, 28, 29, 31 e 32. Desta forma, aproximadamente 70\% das afirmações do SEEQ tiveram redução nos seus desvios padrão para os alunos das turmas 03 e 04 . Se incluirmos também os desvios padrão que se mantiveram praticamente iguais (afirmações 1, 14, 21, 27 e 30), teremos aproximadamente $85 \%$ de todas as afirmações do SEEQ.

Com essa comprovação estatística, a metodologia de ensino proposta, aplicada nas turmas 03 e 04, tem demonstrado não apenas uma melhora significativa na percepção dos alunos sobre a efetividade do ensino realizado na disciplina, mas também que essa percepção tem sido mais coesa, mais homogênea e mais convergente em relação a metodologia de ensino que estava sendo adotada anteriormente (turmas 01 e 02).

O teste estatístico não paramétrico Wilcoxon-Mann-Whitney, apresentado na figura 5, foi realizado com o auxílio da linguagem de programação $R$ para verificar a equivalência das respostas dos alunos quanto ao questionário SEEQ preenchido para as turmas 01, 02, 03 e 04. Na figura 5(a) realiza-se a comparação dos resultados obtidos entre as turmas 01 e $02(01 / 02)$ e a comparação entre as turmas de 03 e 04 (03/04). Na figura 5(b) realiza-se a comparação entre as turmas 02 e 03 $(02 / 03)$.

Vale observar que as turmas 03/04 referem-se aos alunos que cursaram a disciplina com a 


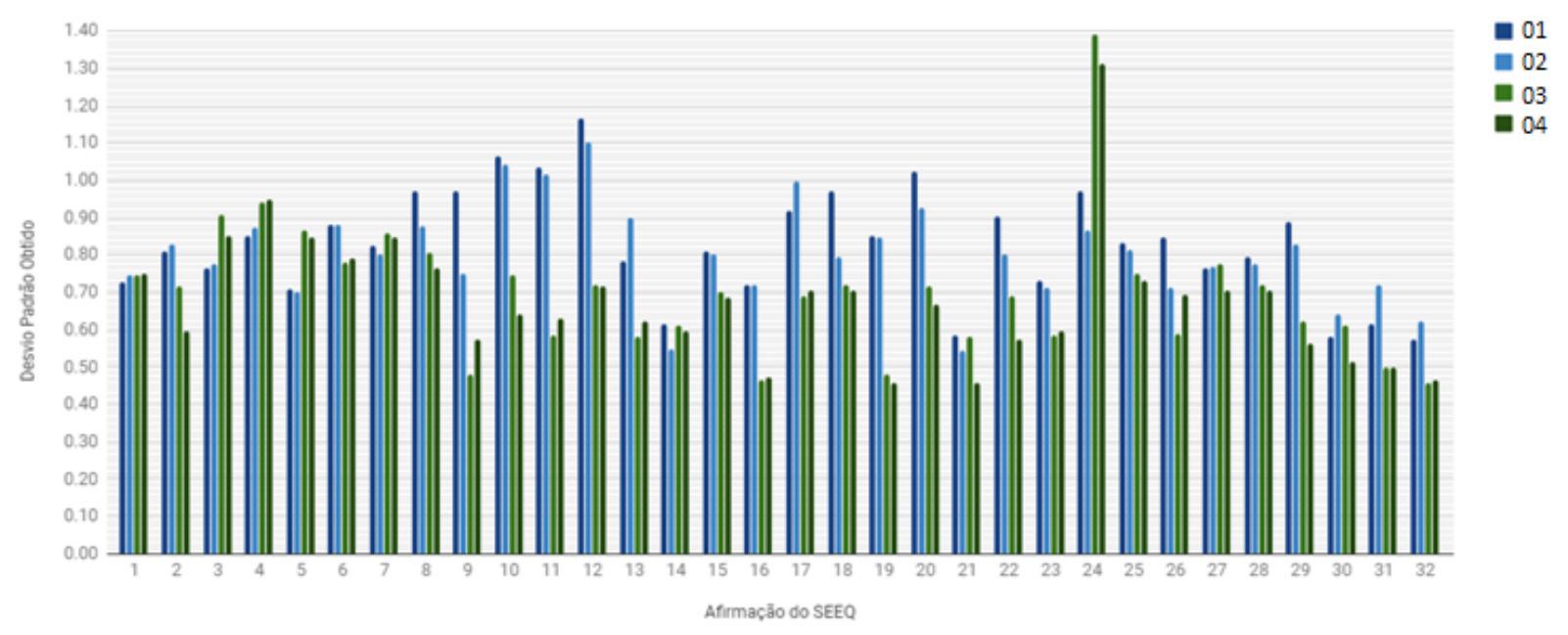

Figura 4: Desvio padrão das respostas obtidas em cada afirmação do SEEQ para as turmas 01, 02, 03 e 04.

metodologia de ensino descrita na seção 3 deste artigo, enquanto que as turmas 01/02 referem-se a metodologia de ensino anteriormente adotada, como descrito na subseção 5.1. Por sua vez, o teste realizado nas turmas 02/03 da figura 5(b) corresponde ao momento de mudança da metodologia de ensino adotada na disciplina, comparando-se, portanto, a metodologia de ensino que estava sendo adotada anteriormente (representada pelos alunos da turma 02) com a metodologia de ensino proposta (representada pelos alunos da turma 03).

É interessante observar, no gráfico da figura 5(a), que todos os p-valores produzidos com a realização do teste estatístico são maiores que o nível de significância estabelecido $(0,05)$ tanto para as turmas 01/02 quanto para as turmas 03/204. Sendo assim, a hipótese nula do teste não é rejeitada, evidenciando a equivalência das amostras comparadas: as respostas da turma 01 sendo consideradas equivalentes às respostas da turma 02 e as respostas da turma 03 sendo equivalentes às respostas da turma 04. Particularmente, esse resultado estatístico mostra-se em consonância com as metodologias de ensino aplicadas, já que as turmas 01 e 02 estão relacionadas à aplicação de uma mesma metodologia de ensino, o que também é válido para as turmas 03 e 04 , no entanto, neste último caso, estando relacionadas com a aplicação da metodologia de ensino proposta.

Por sua vez, ao se comparar estatisticamente a turma 02 com a turma 03 , momento em que ocorreu a mudança na metodologia de ensino aplicada na disciplina, um resultado diferente é produzido, como apresentado na figura 5(b). Note-se que muitos p-valores obtidos são menores do que o nível de significância delineado (linha tracejada no gráfico), rejeitando-se, portanto, a hipótese nula de equivalência em aproximadamente $65 \%$ de todo o questionário SEEQ respondido pelos alunos (diferenças estatísticas significativas foram encontradas nas afirmações af_1, af_2, af_3, af_4, af_8, af_9, af_10, af_11, af_12, af_13, af_14, af_15, af_16, af_21, af_22, af_23, af_26, af_27, af_30, af_31 e af_32). Assim, esse resultado estatístico evidencia que a percepção dos alunos quanto a efetividade do ensino realizado foi alterada quando se aplicou a metodologia 


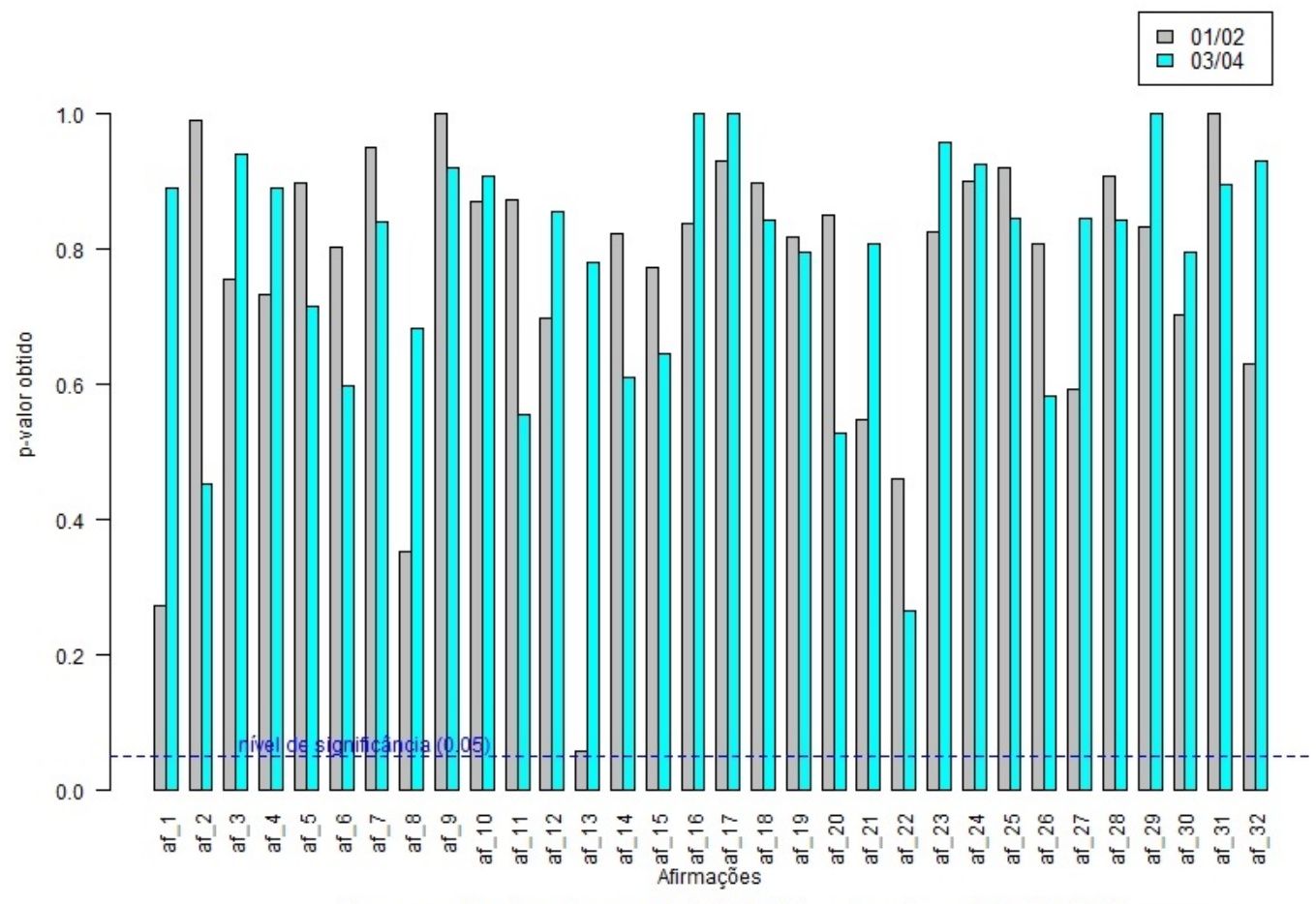

(a) comparação entre as turmas 01 e $02(01 / 02)$ e entre as turmas 03 e $04(03 / 04)$

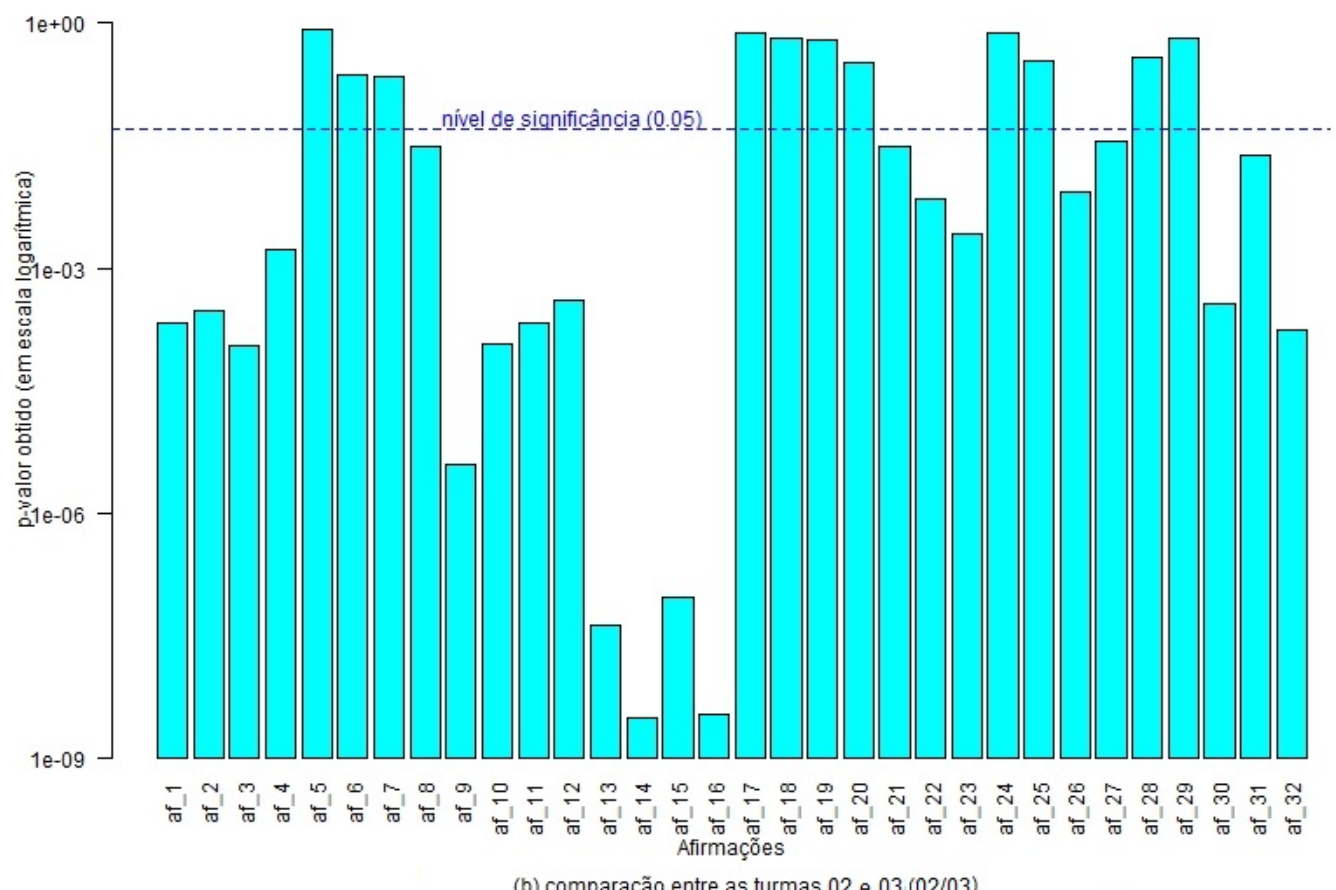

(b) comparação entre as turmas 02 e $03(02 / 03)$

Figura 5: Teste de Wilcoxon-Mann-Whitney quanto a equivalência das amostras dos resultados do questionário SEEQ. 
de ensino proposta.

No entanto, a comprovação estatística de que a percepção dos alunos sobre o ensino realizado foi alterada não é suficiente, também se faz necessário verificar se essa percepção foi considerada pior ou melhor pelos alunos.

Tendo em vista que, com exceção da última dimensão do questionário SEEQ da tabela 2, quanto maior a escala escolhida melhor é o grau de satisfação ou de aprendizado percebido pelo aluno. Para a última dimensão, quanto menor o valor da escala escolhida menor a carga de trabalho ou dificuldade percebida pelo aluno. Sendo assim, dois testes estatísticos foram executados sobre o questionário SEEQ: um teste levando em consideração a hipótese alternativa de superioridade comparando-se as respostas da turma 03 com as respostas da turma 02 (figura 6(a)) e; um outro teste levando em consideração a hipótese alternativa de inferioridade comparando-se as respostas da turma $03 \mathrm{com}$ as respostas da turma 02 (figura 6(b)).

De acordo com a figura 6(a), muitos p-valores calculados são menores do que o nível de significância delineado em 0,05, aceitando-se assim, a hipótese alternativa de superioridade em várias afirmações respondidas pelos alunos da turma 03 em comparação aos alunos da turma 02. Esse fato estatístico demonstra que não apenas a percepção dos alunos quanto ao ensino foi alterada, mas que também os alunos consideram ter tido um melhor grau de satisfação ou de aprendizado percebido quando da aplicação da metodologia de ensino proposta.

As principais dimensões em que ocorreu uma melhora na percepção dos alunos foram: aprendizado (todas as quatro afirmações), organização (todas as quatro afirmações), interação com o grupo (todas as quatro afirmações), amplitude na abordagem (afirmações 21, 22 e 23) e o processo de avaliação (afirmações 26 e 27).

Dentro deste contexto, é interessante observar que nas dimensões de entusiasmo e empatia, por exemplo, a metodologia de ensino proposta teve pouca ou nenhuma influência, não alterando significativamente as respostas obtidas entre a turma 02 e a turma 03 , como pode ser comprovado na 6(a) e na figura 5(b) em que demonstra-se a equivalência entre a maioria das afirmações correspondentes a essas duas dimensões. Provavelmente, a pouca ou nenhuma influência observada refere-se ao fato de que essas duas dimensões são muito mais relacionadas às características interpessoais e de comportamento do professor da disciplina do que relacionadas à metodologia de ensino-aprendizagem aplicada.

Para a última dimensão do questionário SEEQ sobre a carga de trabalho e dificuldade percebidas pelos alunos, têm-se os resultados apresentados na figura 6(b). Das três afirmações correspondentes a essa dimensão (afirmações 30, 31 e 32), o p-valor calculado para a afirmação 30 é menor do que o nível de significância delineado, aceitando-se, portanto, a hipótese de inferioridade nas respostas da turma 03 em comparação às respostas da turma 02 . 


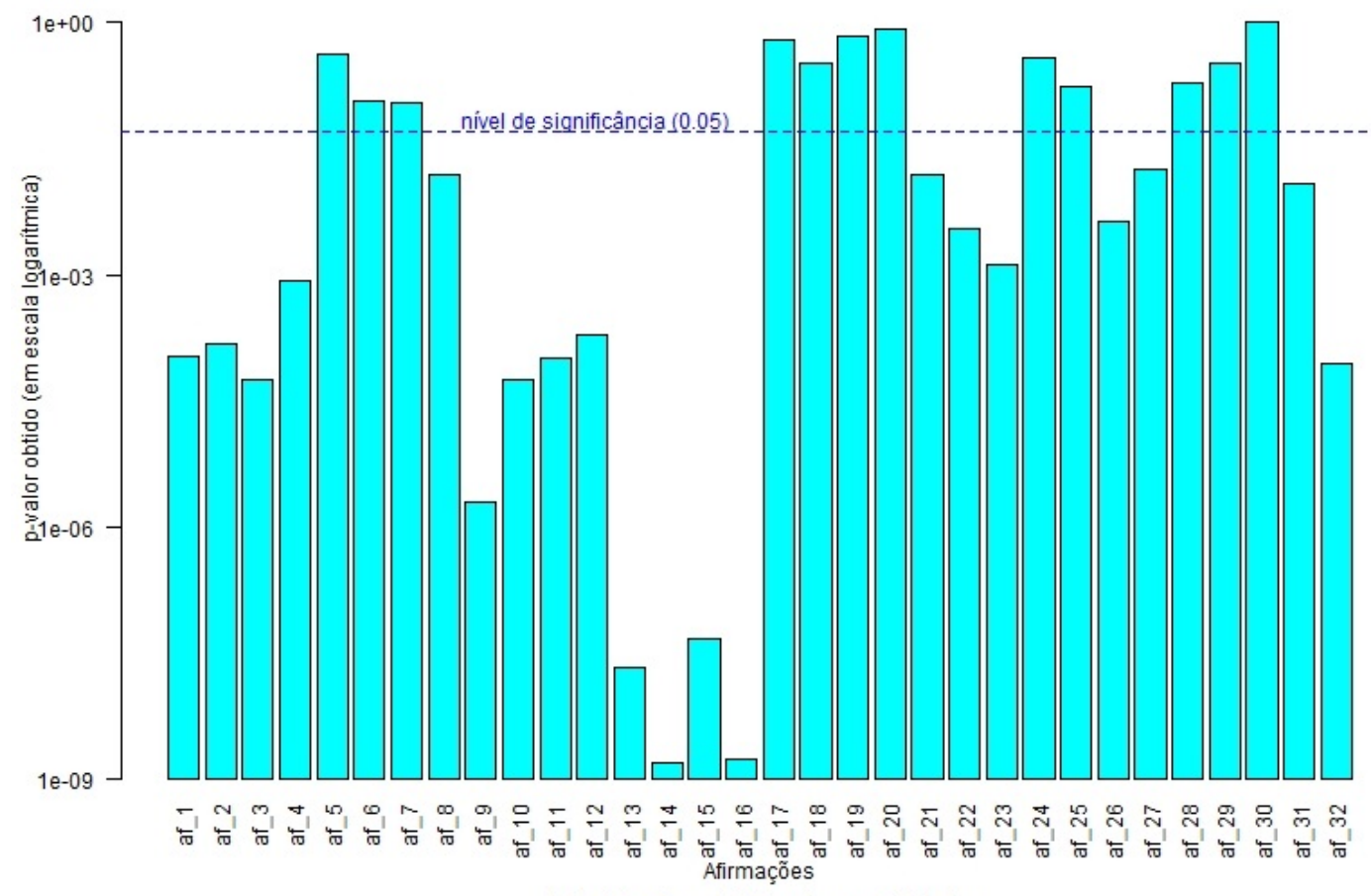

(a) verificação estatística de superioridade

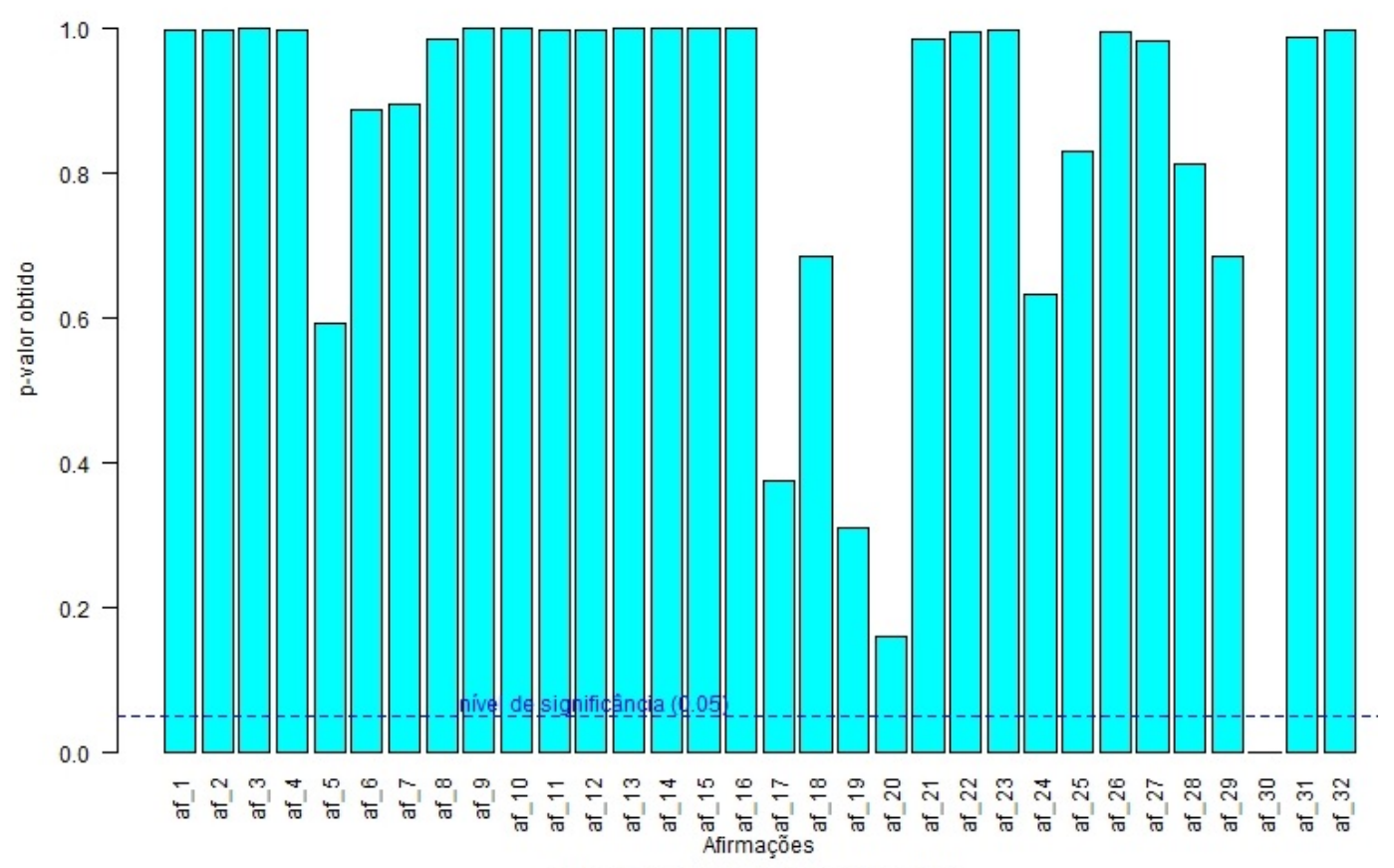

(b) verificação estatística de inferioridade

Figura 6: Diferença nas respostas do SEEQ entre a turma 03 e a turma 02. 


\subsection{Análise de Uso do Ambiente Virtual de Aprendizagem Moodle}

A metodologia de ensino-aprendizagem proposta neste artigo e aplicada às turmas 03 e 04 foi suportada pelo uso do ambiente virtual de aprendizagem Moodle, mais especificamente, da ferramenta denominada Laboratório de Avaliação (Workshop) $)^{4}$.

A ferramenta Laboratório de Avaliação, ao ser lançada no Moodle como uma atividade, permite o recebimento de arquivos (neste caso, de relatórios técnicos) produzidos pelos alunos e, posteriormente, permite atribuí-los a avaliação de pares. Para o processo de avaliação dos pares, um formulário de avaliação com critérios definidos pelo professor responsável (neste caso, a ficha de avaliação elaborada na tabela 1) pode ser estabelecido. Ao término dessa atividade, os alunos obterão dois conceitos: um para o arquivo enviado e outro para a avaliação colaborativa realizada.

Na figura 7 pode-se observar a visão geral do professor quando da realização da atividade Laboratório de Avaliação para o Ponto de Checagem PC4.

\section{Ponto de checagem 4 - Integral $\odot$}

\section{Encerrado}

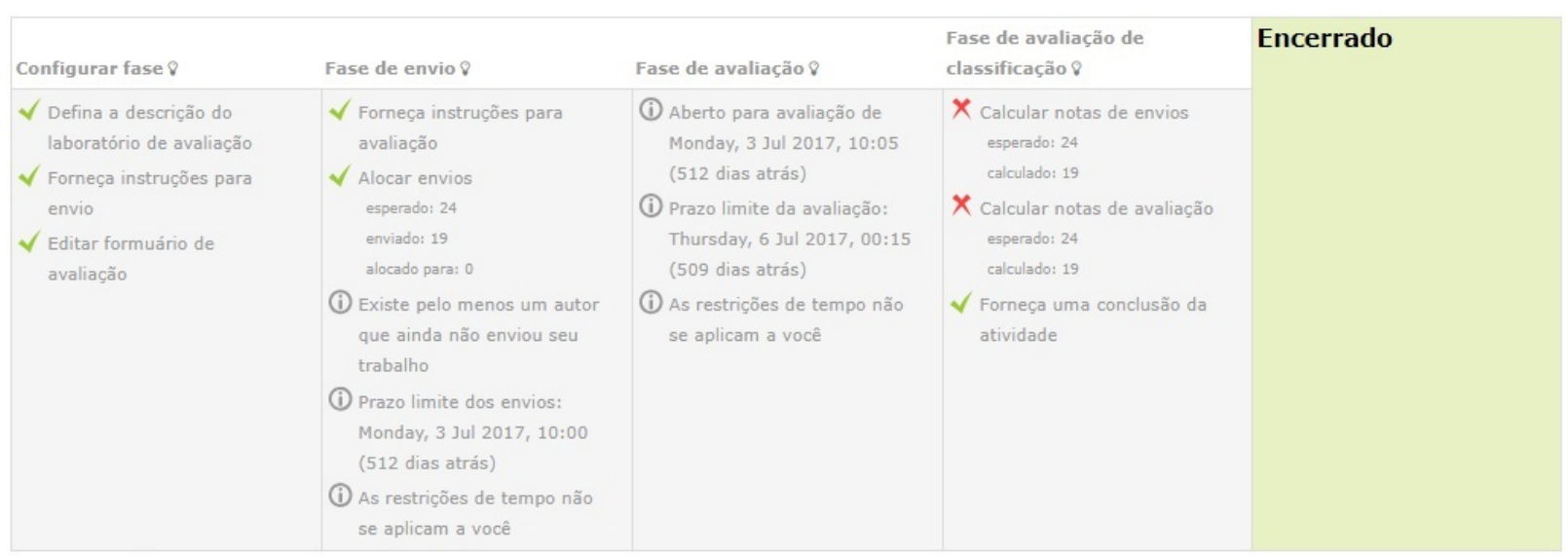

Conclusão -

Avaliação Finalizada!

Figura 7: Visão geral do professor responsável pelo lançamento da atividade Laboratório de Avaliação no Ponto de Checagem PC4.

Tecnicamente, a atividade estrutura-se em quatro fases, sendo elas: "Configurar fase", "Fase de envio", "Fase de avaliação" e "Fase de avaliação de classificação". Em "Configurar fase", deve-se organizar as orientações da atividade e também do critério de avaliação, configurando-se a ficha de avaliação da tabela 1. Em "Fase de envio", quando habilitada, permite aos alunos o envio de seus relatórios técnicos. Após o envio dos relatórios técnicos, deve-se configurar

\footnotetext{
${ }^{4}$ Mais detalhes sobre o Laboratório de Avaliação podem ser encontrados no endereço eletrônico https://docs.moodle.org/37/en/Workshop_activity, acessado em 20/05/2019.
} 
o processo de avaliação colaborativa por meio da alocação e distribuição dos avaliadores para cada relatório técnico submetido. Em "Fase de avaliação", a ferramenta permite que os alunos avaliem os relatórios técnicos que foram atribuídos a eles na fase anterior. Por último, em "Fase de avaliação de classificação", serão publicados os conceitos obtidos pelos alunos na realização dessa atividade, bem como serão disponibilizados pela ferramenta, para cada aluno que confeccionou um relatório técnico, as respectivas fichas de avaliação preenchidas pelos avaliadores.

Dentro deste contexto, vale comentar que o uso da ferramenta Laboratório de Avaliação otimizou a aplicação da metodologia de ensino se comparado a uma abordagem mais manual. A ferramenta possibilitou a automatização de várias etapas do processo de avaliação colaborativa, facilitando desde a coleta e organização dos relatórios técnicos, a distribuição e preenchimento das fichas de avaliação até a publicação dos conceitos obtidos e disponibilização dos retornos formativos aos alunos.

No entanto, embora a ferramenta tenha facilitado a aplicação da metodologia de ensinoaprendizagem, pode-se apontar os seguintes fatos e limitações:

1. Embora a ferramenta disponibilize aos alunos um diagrama contendo uma visão geral da atividade, como pode ser observado na figura 8 para o PC2 aplicado, constatou-se que alunos tanto da turma 03 quanto da turma 04 tiveram dificuldades ou confusão em relação às suas atribuições e prazos de tarefas que deveriam ser executadas durante o processo de avaliação colaborativa.

\section{Ponto de Checagem PC2 3}

\section{Encerrado}

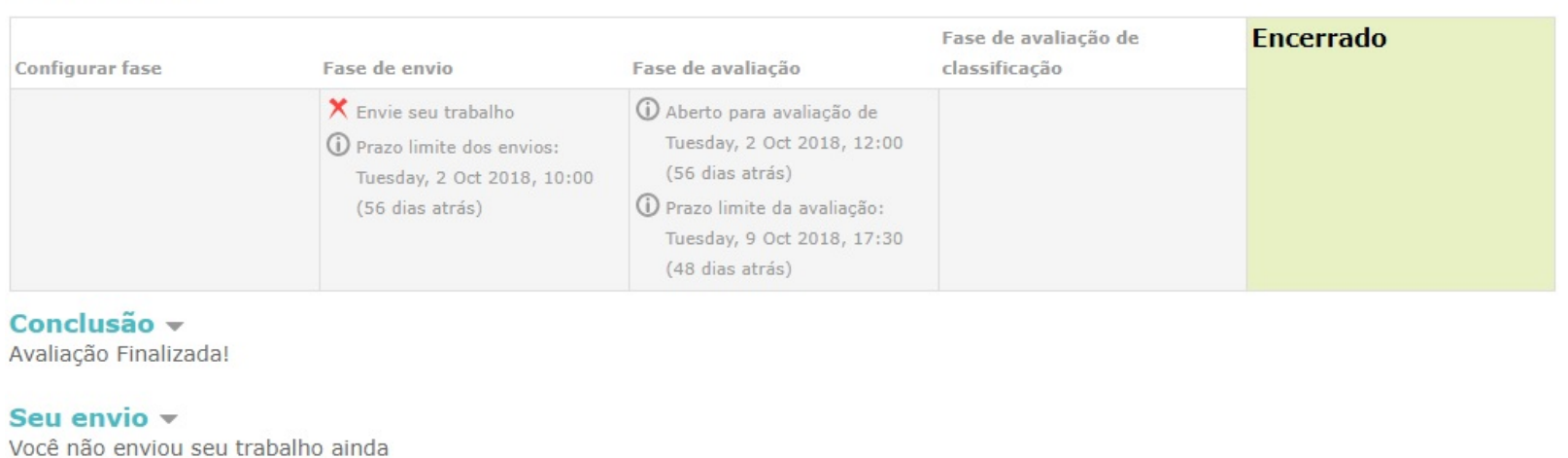

2. Após os encerramentos de avaliações colaborativas, um total de aproximadamente $30 \%$ dos alunos de ambas as turmas perguntaram ao professor responsável como e onde acessar as 
fichas de avaliação que foram preenchidas pelos avaliadores de seus relatórios técnicos, já que não estavam encontrando-as na ferramenta. Esse fato pode ser um indício de que a ferramenta deve ser aprimorada visando uma maior usabilidade do sistema.

3. A ferramenta, de forma automática, envia ao aluno as respectivas fichas de avaliação preenchidas de seu relatório técnico submetido, não permitindo ao aluno identificar a autoria das avaliações realizadas, mantendo-se, assim, o anonimato dos avaliadores (revisão cega). Conquanto, não há a opção de manter o anonimato tanto do avaliador quanto do autor do relatório técnico (revisão duplo-cega), o que seria mais adequado para a metodologia de ensino-aprendizagem proposta neste artigo.

4. A ferramenta Laboratório de Avaliação limita-se, basicamente, a realizar uma alocação manual ou uma alocação automática aleatória de avaliadores, não disponibilizando outras opções de alocação. Para a realização da metodologia de ensino-aprendizagem descrita neste artigo, como comentado na seção 4, a cada novo PC, atribuem-se relatórios técnicos de diferentes alunos, buscando-se evitar a repetição de alunos em relação aos pontos de checagem anteriores para um determinado avaliador. Sendo assim, seria interessante se fosse possível optar pela realização de uma alocação automática aleatória, mas que levasse em consideração a não repetição de avaliadores entre os pontos de checagem.

\section{Considerações Finais}

Neste artigo apresentou-se uma metodologia de ensino estruturada em avaliações colaborativas para relatórios técnicos combinadas com a utilização de rubricas na definição de fichas de avaliação na tentativa de construir um ambiente didático que permita o aprimoramento da habilidade de escrita dos alunos. Como pôde ser constatado, essa abordagem de ensino-aprendizagem aplicada numa disciplina de um curso de Engenharia de Computação tem proporcionado a confecção de relatórios técnicos melhores se comparados com os relatórios produzidos numa abordagem de ensino tradicional, fomentando a interação entre os alunos, onde, por meio do preenchimento das fichas de avaliação, novos caminhos, alternativas, melhorias, ajustes e adequações são efetivados, estimulando-se, com isso, o senso crítico e a capacidade de auto-avaliação dos alunos ao analisarem os relatórios técnicos confeccionados pelos seus pares. Além disso, com a aplicação do questionário SEEQ, tem se constatado estatisticamente não apenas uma melhora na percepção dos alunos sobre a qualidade do ensino empregado na disciplina, mas também que essa percepção tem sido mais uniforme e convergente em relação à metodologia de ensino que estava sendo anteriormente adotada.

Como trabalho futuro, buscar-se-á estender e ampliar a aplicação da metodologia de ensino abordada na seção 3 para outras disciplinas do curso de Engenharia de Computação e em outros cursos da Unifesp. Assim, será possível observar com mais detalhes o comportamento da metodologia e sua influência em um conjunto de disciplinas. 
Dentro deste contexto, vale ressaltar a capacidade de escalabilidade da metodologia de ensino-aprendizagem proposta neste artigo: com o processo de avaliação dos relatórios técnicos sendo compartilhado e distribuído com toda a turma, é possível aplicar a metodologia em disciplinas que possuem uma quantidade razoável de alunos. No entanto, se houver a intenção de que cada aluno tenha contato com todos os trabalhos que estão sendo desenvolvidos pelos demais alunos da turma, quanto maior o tamanho dessa turma, maior será a quantidade de relatórios técnicos que deverão ser atribuídos para cada avaliador. Dependendo do tamanho da turma, mesmo com o aumento na quantidade de relatórios técnicos por avaliador, pode-se tornar inviável garantir que cada aluno tenha contato com todos os trabalhos que estão sendo realizados pela turma.

No caso oposto, se a turma for muito pequena, pode não ser muito adequado cada relatório técnico ser avaliado por apenas um ou dois alunos, pois poderá ser gerada uma quantidade insuficiente de retornos formativos derivados das poucas fichas de avaliação preenchidas, levando a falhas na triangularização das informações disponibilizadas. Portanto, um estudo interessante que pode ser realizado refere-se à escalabilidade da metodologia de ensino proposta e a sua relação com a quantidade de fichas de avaliação atribuída por relatório técnico frente aos resultados de aprendizado de comunicação escrita apresentados pelos alunos.

Além disso, uma questão que merece um estudo mais aprofundado refere-se à inclusão de outras dimensões na ficha de avaliação para buscar o aprimoramento de algumas competências específicas. Por exemplo, a definição de uma dimensão sobre reflexão poderia fomentar, encorajar e intensificar ainda mais a auto-reflexão dos alunos. Seria interessante, portanto, a análise da inclusão dessa dimensão sobre o aprendizado dos alunos.

Por fim, a metodologia de ensino proposta também pode ser adaptada para ser aplicada em apresentações orais, buscando-se aprimorar não apenas a habilidade de comunicação escrita dos alunos, mas também a igualmente importante habilidade de comunicação verbal.

\section{References}

Andrade, H. (2000, feb). Using rubrics to promote thinking and learning. Educational Leadership, 57(5), 13-18. [GS Search]

Campbell, A. (n.d., oct). Application of ICT and rubrics to the assessment process where professional judgement is involved: the features of an e-marking tool. Assessment \& Evaluation in Higher Education(5), 529-537. doi: https://doi.org/10.1080/02602930500187055 [GS Search]

Coffey, M., \& Gibbs, G. (2001). The evaluation of the student evaluation of educational quality questionnaire (seeq) in uk higher education. Assessment \& Evaluation in Higher Education, 26(1), 89-93. doi: https://doi.org/10.1080/02602930020022318 [GS Search]

Ferreira, D., \& Silva, A. (2010). Avaliação de um web fórum por meio de rubricas. Revista Meta: Avaliação, 2(4), 87-127. [GS Search] 
Florian-Gaviria, B., Glahn, C., \& Fabregat Gesa, R. (2013, jul). A Software Suite for Efficient Use of the European Qualifications Framework in Online and Blended Courses. IEEE Transactions on Learning Technologies, 6(3), 283-296. doi: https://doi.org/10.1109/TLT.2013.18 [GS Search]

França, A. S. (2013). Comunicação Escrita Nas Empresas - Teorias e Práticas. Atlas. [GS Search]

Garousi, V. (2010, may). Applying Peer Reviews in Software Engineering Education: An Experiment and Lessons Learned. IEEE Transactions on Education, 53(2), 182-193. doi: https://doi.org/10.1109/TE.2008.2010994 [GS Search]

Huba, M. E., \& Freed, J. E. (2000). Learner-centered Assessment on College Campuses: Shifting the Focus from Teaching to Learning (8th ed.). Allyn and Bacon. [GS Search]

Lobato, A. S., Brito, S. R., Souza, D. N. N., \& Favero, E. L. (2009). Um sistema gerenciador de rubricas para apoiar a avaliação em ambientes de aprendizagem. In Xx simpósio brasileiro de informática na educação. Florianópolis/SC. [GS Search]

Marsh, H. (1982, 05). Seeq: A reliable, valid, and useful instrument for collecting students' evaluations of university teaching. British Journal of Educational Psychology, 52, 77 - 95. doi: https://doi.org/10.1111/j.2044-8279.1982.tb02505.x [GS Search]

McGoldrick, K., \& Peterson, B. (2013, jan). Using rubrics in economics. International Review of Economics Education, 12, 33-47. doi: https://doi.org/10.1016/j.iree.2013.04.009 [GS Search]

Ng, E. M. W. (2014, apr). Using a mixed research method to evaluate the effectiveness of formative assessment in supporting student teachers' wiki authoring. Computers \& Education, 73, 141-148. doi: https://doi.org/10.1016/j.compedu.2013.12.016 [GS Search]

Oliveira, T., Martins, L. E. G., Stringhini, D., Fazenda, A. L., \& Cappabianco, F. A. M. (2017). O ensino e aprendizado de Arquitetura e Organização de Computadores num currículo de Engenharia de Computação estruturado em uma abordagem prática e sistêmica. International Journal of Computer Architecture Education (IJCAE), 6(1), 27-36. [GS Search]

Oliveira, T., Stringhini, D., Craibas, J. J. S., \& Corrêa, D. G. M. (2018, 10). Metodologia de ensino baseada em avaliações colaborativas e rubricas para o aprimoramento da habilidade de escrita de relatórios técnicos em cursos de graduação. In (p. 1603). doi: http://dx.doi.org/10.5753/cbie.sbie.2018.1603 [GS Search]

Reddy, Y. M., \& Andrade, H. (2010, jul). A review of rubric use in higher education. Assessment \& Evaluation in Higher Education, 35(4), 435-448. doi: https://doi.org/10.1080/02602930902862859 [GS Search]

Richardson, J. T. E. (2005). Instruments for obtaining student feedback: a review of the literature. Assessment \& Evaluation in Higher Education, 30(4), 387-415. doi: https://doi.org/10.1080/02602930500099193 [GS Search]

Silva, E., \& Moreira, D. (2003, mar). WebCoM: A Tool to Use Peer Review to Improve Student Interaction. Journal on Educational Resources in Computing, 3(1). doi: https://doi.org/10.1145/958795.958798 [GS Search] 
Tenório, T., Bittencourt, I. I., Isotani, S., \& Silva, A. P. (2016). Does peer assessment in on-line learning environments work? a systematic review of the literature. Computers in Human Behavior, 64, 94 - 107. doi: https://doi.org/10.1016/j.chb.2016.06.020 [GS Search]

Topping, K. (2006). Self and Peer Assessment in School and University: Reliability, Validity and Utility. In Optimising new modes of assessment: In search of qualities and standards (pp. 55-87). Dordrecht: Kluwer Academic Publishers. doi: https://doi.org/10.1007/0-30648125-1_4 [GS Search]

Trahasch, S. (2004). From peer assessment towards collaborative learning. In 34th annual frontiers in education, 2004. fie 2004. (pp. 774-778). Savannah, GA, USA: IEEE. doi: https://doi.org/10.1109/FIE.2004.1408638 [GS Search]

Ugulino, W., Marques, A. M., Pimentel, M., \& Siqueira, S. W. (2009). Avaliação Colaborativa: um Estudo com a Ferramenta Moodle Workshop. In Xx simpósio brasileiro de informática na educação. Florianópolis/SC. [GS Search]

Wang, Y., Li, H., Feng, Y., Jiang, Y., \& Liu, Y. (2012). Assessment of programming language learning based on peer code review model: Implementation and experience report. Computers \& Education, 59(2), 412 - 422. doi: https://doi.org/10.1016/j.compedu.2012.01.007 [GS Search]

Zorzo, A. F., Nunes, D., Matos, E. S., Steinmacher, I., Leite, J. C., Araujo, R., ... Martins, S. (2017). Referenciais de Formação para os Cursos de Graduação em Computação. Sociedade Brasileira de Computação (SBC). [GS Search] 